\title{
The effects of iron deficiency and anaemia on primary school learners' scholastic performance
}

\author{
B P S Hlatswayo, ${ }^{1}$ BSc, MMed (Paed); S Ntshangase, ${ }^{2}$ MA; F P R de Villiers, ${ }^{1}$ BA, FCPaed, FACP, PhD \\ ${ }^{1}$ Department of Paediatrics and Child Health, Medical University of South Africa, Sefako Makgatho Health Sciences University (SMU), Pretoria, \\ South Africa \\ ${ }^{2}$ Department of Psychology, University of South Africa, Pretoria, South Africa
}

Corresponding author: F de Villiers (alfafrancois@yahoo.co.uk)

\begin{abstract}
Background. Iron deficiency anaemia (IDA) is a preventable cause of cognitive impairment and other negative effects on the academic potential of learners.

Objectives. To determine the local prevalence of IDA among grade 2 learners in a resource-poor community and to evaluate the association between IDA and the learners' scholastic performance.

Methods. This was a case-control observational design study. Data were collected using a stadiometer and an electronic scale, HemoCue $\mathrm{Hb} 201^{+}$system and official grade 1 school reports.

Results. The point prevalence of IDA was found to be $9.8 \%(n=19)$, with a higher prevalence among girls $(58 \%)$. There was no statistically significant difference between the performances of the two groups $(p=0.511)$ in mathematics. There was a statistically significant difference for life skills $(p=0.00017)$, and the difference between the groups in literacy or languages approached statistical significance $(p=0.071)$.

Conclusions. The results of this study suggest that IDA is prevalent and may have negative effects on learners' scholastic performances. Such negative effects warrant early preventive measures so as to avoid the possibilities of school failure, drop-out and poor productivity in adulthood.
\end{abstract}

S Afr J Child Health 2016;10(2):111-115. DOI:10.7196/SAJCH.2016.v10i2.887

Iron deficiency (ID) is the most common nutritional disorder in the developing world and, as a result, a large number of children under the age of 5 years do not reach their developmental potential. ${ }^{[1,2]}$ ID and ID anaemia (IDA) are widespread health problems among children. Approximately $40 \%$ of children are anaemic across various African and Asian settings. ${ }^{[2]}$ South African (SA) studies have indicated a high national prevalence of IDA among children; rural children were found to have the highest prevalence (43.2\%) of ID. ${ }^{[3]}$ A study conducted in disadvantaged communities in the Western Cape found $32 \%$ of coloured infants and $46 \%$ of black infants to have IDA, ${ }^{[4]}$ while Van Stuijvenberg et al. ${ }^{[5]}$ found a prevalence of $27.8 \%$ among 6 - 11-year-old primary school learners in KwaZulu-Natal (KZN) Province, and the most recent study, done in Kimberley in the Northern Cape Province, found the prevalence of ID to be 30.6\%. ${ }^{[6]}$

Iron is an essential micronutrient necessary for maintaining the normal structure and function of virtually all cells of the body. It is a component of many proteins, including $\mathrm{Hb}$, which is important for transporting oxygen to tissues throughout the body. Oxygen is poorly soluble in plasma and the iron atoms in the haem group of $\mathrm{Hb}$ can bind reversibly to oxygen molecules, thus providing transport to $98.5 \%$ of the total oxygen to body tissues. ${ }^{[7]}$ Total body balance depends on dietary uptake and gastrointestinal loss of iron. No organ performs the physiological role of iron excretion; $~ 1 \mathrm{mg}$ of iron is lost each day through sloughing of cells from mucosal surfaces and the skin. Consequently, absorption is the sole means of regulating body iron stores rather than control of excretion. ${ }^{[7]}$

ID develops gradually. ID without anaemia occurs when $\mathrm{Hb}$ synthesis is impaired but $\mathrm{Hb}$ levels have not fallen sufficiently to meet the definition of anaemia. The first stage entails the depletion of iron stores, leading to reduced ferritin levels. This reflects a decrease in iron concentration in the liver, spleen and bone marrow. This is followed by iron-deficient erythropoiesis, whereby erythroid iron supply is diminished, but $\mathrm{Hb}$ remains in the normal range. There is a reduction of mean corpuscular volume and mean corpuscular $\mathrm{Hb}$ and low serum iron with low transferrin saturation. The third stage is IDA, where the low iron supply restricts $\mathrm{Hb}$ production leading to the development of detectable anaemia. Features include low $\mathrm{Hb}$ values, reduced red blood cell size and reduced transferrin saturation $(<16 \%) \cdot{ }^{[8]}$

According to the Centers for Disease Control and Prevention (CDC) in the USA, ${ }^{[9]}$ IDA leads to weakness, poor physical growth and a compromised immune system. It also impairs cognitive performance and delays psychomotor development. However, IDA is a preventable cause of cognitive impairment and other negative effects on the academic potential of children. For instance, Angeles et $a l .{ }^{[10]}$ reported improved growth in iron-deficient preschool learners following iron supplementation in Indonesia. The developmental deficits related to IDA can to some extent be corrected with iron treatment. However, some deficits are not reversible with iron treatment. Irreversible developmental delays in children and the fact that iron is needed continuously throughout the entire period of brain growth are strong arguments for the active and effective combatting and prevention of ID. The highest risk of IDA occurs during periods of rapid growth and nutritional demand. Therefore infants, children and adolescents are likely to be the most affected. ${ }^{[4]}$

The association of IDA and poor scholastic performance has been well studied internationally, ${ }^{[11,12]}$ with some of the studies focusing on learning areas such as mathematics ${ }^{[13-15]}$ and life skills or general knowledge. ${ }^{[12,16]}$ However, in SA, despite the high prevalence of IDA, there are limited data on the association of IDA and school performance. Therefore this study intended to determine the local prevalence of IDA among grade 2 learners and investigate whether the association of IDA and poor school performance holds true for SA primary schoolgoing children.

The hypothesis was that participants from the control group would perform better in three selected school subjects than in the case group. The study was to be done in a local community in the Winterveldt area, north of Pretoria in the Gauteng Province of SA. Winterveldt is a historically disadvantaged peri-urban area, which is typically characterised by poverty, low standards of living and low socioeconomic conditions. The last SA census estimated the population of Winterveldt as 120 826, with $30.9 \%$ under the age of 
15 years (i.e. 37335 children). ${ }^{[17]}$ There are 24 primary schools in the area, and each primary school has $\sim 120$ learners in grade 2 in each year. ${ }^{[18]}$ There are no private schools in the area.

\section{Methods}

This quantitative study used a case-control observational design. The sample was selected from primary schoolgoing learners doing grade 2 in three public sector primary schools, which were accessible from the university and close to each other. All grade 2 learners from each of the targeted schools were screened for ID, by using a finger-prick $\mathrm{Hb}$ meter. Two groups resulted from this screening procedure: group A with no anaemia $(\mathrm{Hb}>11.5 \mathrm{~g} / \mathrm{dL})$ and group $\mathrm{B}$ with anaemia. Further testing was done on the anaemic group to determine iron status, using ferritin and C-reactive protein (CRP). IDA was diagnosed in learners with $\mathrm{Hb}<11.4 \mathrm{~g} / \mathrm{dL}$, low ferritin levels $(<12 \mu \mathrm{g} / \mathrm{L})$ and normal CRP $(<10 \mathrm{mg} / \mathrm{L})$. Severe non-IDA was defined as $\mathrm{Hb}<10 \mathrm{~g} / \mathrm{dL}$ (severe anaemia), with normal ferritin levels $(>12 \mu \mathrm{g} / \mathrm{L})$ and normal CRP $(<10 \mathrm{mg} / \mathrm{L})$, i.e. such learners did not have ID. After blood results were available, controls and cases were recruited at a 2:1 ratio by attempting to match anthropometry. The learners with ferritin lower than $12 \mu \mathrm{g} / \mathrm{L}$ (with IDA) and those with severe non-IDA were identified as cases. The controls were taken from group A (the non-anaemic group). Hb increases with age, and by definition 1 - 6 year-olds must have $\mathrm{Hb}<11.5 \mathrm{~g} / \mathrm{dL}$ to be classified as anaemic. Sex was used as an independent variable as there is no sex difference in $\mathrm{Hb}$ values for children $<12$ years of age ${ }^{[14]}$ For the purpose of maintaining anonymity, study numbers ranging from 1 to 194 were allocated to participants. The research instruments that were used for data collection were a Seca 214 (Seca, Germany) height measuring device. Height was measured to the nearest millimetre and weight was measured using a Safeway electronic digital scale, model EB727 (Safeway, South Africa), which records weight to the nearest decigram. Subjects were weighed without shoes and heavy clothing such as jerseys and jackets. These measurements were done twice to ensure data quality.

The HemoCue $\mathrm{Hb} 201^{+}$system was used for the screening of all participants. The test entails collecting a drop of blood by finger-prick onto a test strip with immediate $\mathrm{Hb}$ value displayed. The HemoCue $\mathrm{Hb} 201^{+}$system provides quick, simple and accurate quantitative $\mathrm{Hb}$ results with the same performance as a large haematology analyser. ${ }^{[19-21]}$ It has an internal electronic self-test. When the analyser is turned on, it will automatically verify the performance of the optronic unit. Other benefits include no calibration between cuvette batches and it can automatically compensate for turbidity due to lipids and leukocytosis. ${ }^{[22]}$

Official grade 1 school reports were collected from each school after cases and controls were identified and recruited. All reports were of the standard format that is prescribed for all public primary schools in SA. A national coding system is used for all the foundation phase years, and learners are tested on three areas: literacy (languages), numeracy (mathematics) and life skills (life orientation). Each learner is allocated a score from 1 to 4 for each of the three subjects separately, where 1 means that competence was not achieved, 2 represents partial achievement, 3 represents satisfactory achievement and 4 is for excellent achievement. Assessment is done for each of the four terms of the school year. The maximum total for each term (terms 1, 2, 3 and 4) is 12 points. Not all learners had reports for all four terms, so analysis of school performance was done as the average of each school subject over the four terms. Therefore the maximum total obtainable by each participant was 12 points. Each participant's rating scores were then recorded as an indication of participants' scholastic performances.

Participants found to be anaemic were enrolled for iron status testing. Blood for ferritin levels and CRP was collected to define IDA ( $4 \mathrm{~mL}$ of blood per subject). CRP test was done to rule out acute infection/inflammation, which could have resulted in falsely elevated ferritin. Blood samples were transported in a cooler box to the teaching hospital's National Health Laboratory Services as soon as possible for further testing. Blood results were recorded on the data sheet. Once blood results were available, the participants were allocated to either the experimental or the control group. In addition to the learners who had ferritin $<12 \mu \mathrm{g} / \mathrm{L}$ and CRP $<10 \mathrm{mg} / \mathrm{L}$ (learners with IDA, for example), learners with severe anaemia but with normal ferritin levels were also included in the experimental group; these were labelled non-IDA. Therefore, a case refers to those subjects with IDA and also to those subjects with severe non-IDA.

Learners who were found to have IDA or severe anaemia were referred to the hospital where further tests, including full blood count and HIV enzyme-linked immunosorbent assay, were done. None of the learners had an HIV-positive test result. Learners with proven IDA were started on iron supplements as per the guidelines for weight (10 - $18 \mathrm{~kg}$ : $200 \mathrm{mg} \mathrm{FeSO}$; 18 - $25 \mathrm{~kg}: 300 \mathrm{mg} \mathrm{FeSO}$; 25 $30 \mathrm{~kg}: 400 \mathrm{mg} \mathrm{FeSO}$ ) and vitamin $\mathrm{C}$ (to improve absorption of iron) and were then referred to the local clinic for monthly treatment and given a 6-months follow-up date.

Epi Info software version 3.4.3 (CDC, USA) was used to analyse the results of the study. Information from the data collection sheet comprising the study number, anthropometry, screening $\mathrm{Hb}$, blood tests and marks from school reports were entered twice to ensure data quality. The Data Compare Module of the Epi Info was used to check for differences between the two sets of data and corrections were made. Anthropometric data were entered as the average of the two measurements. School marks were entered as an average of the term mark per subject using the national coding of score $1-4$. The Epi Info software was also used to verify the nutritional status of the learners by using the Nutrition Program to compare our data with the percentiles from the CDC reference data from the National Center of Health Statistics (NCHS); the Epi Info software uses the NCHS data in calculating $z$-scores for individuals. The 50th percentile was taken as the population median. Data from the final study sample of 90 participants were entered and analysed. We computed weight-forage and height-for-age.

The $\chi^{2}$ test was used to test for associations between the variables and to compare the two groups. Comparisons were done between controls and cases in the academic scores, IDA and cognitive function, anthropometry and gender. The $95 \%$ confidence interval was used to test for significance. Other calculations included the means of weight, height, $\mathrm{Hb}$, ferritin, CRP and school marks. The range and standard deviation (SD) were also calculated. Totals of gender and group categories were calculated, as well as frequencies of other parameters such as IDA and anaemia.

\section{Ethics}

Ethical clearance was granted by the Medical University of Southern Africa (MEDUNSA) research ethics committee, Gauteng Department of Education, and the management of the three schools. Parents gave informed consent, learners gave assent, and they could withdraw at any time without providing a reason, or it affecting their schooling. Data collection commenced after permission, assent and informed consent had been obtained. Learners' names were included in this initial screening but recorded at the back of the data sheet for identification during case and control sampling. Only the researchers had access to the data sheet to ensure confidentiality.

\section{Results}

There was a total of 383 grade 2 learners in the three schools: 209 boys and 174 girls. The parents of 189 learners refused consent. A total of 194 learners were enrolled to be screened for anaemia. There were 119 (61.3\%) learners with normal $\mathrm{Hb}$ by definition (World Health Organization: $\mathrm{Hb}>11.5 \mathrm{~g} / \mathrm{dL}$ for 6 - 12-year-olds regardless of sex). 
Table 1. Summary of results

\begin{tabular}{|c|c|c|c|}
\hline & Cases & Controls & Statistical results \\
\hline \multicolumn{4}{|c|}{ Age (months) } \\
\hline Mean & 85.20 & 84.05 & $p=0.807, t=0.868$ \\
\hline Median & 84.00 & 84.00 & \\
\hline Range & $79-99$ & $76-98$ & \\
\hline \multicolumn{4}{|l|}{ Sex, $n(\%)$} \\
\hline Male & $13(43.33)$ & $28(46.66)$ & $p=0.764, \chi^{2}=0.09$ \\
\hline Female & $17(56.66)$ & $32(53.33)$ & \\
\hline \multicolumn{4}{|c|}{ Weight (kg) } \\
\hline Mean & 20.74 & 20.78 & $p=0.484, t=0.04$ \\
\hline Median & 20.50 & 20.40 & \\
\hline Range & $15.60-25.30$ & $15.4-26.5$ & \\
\hline \multicolumn{4}{|c|}{ Height $(\mathrm{cm})$} \\
\hline Mean & 117.28 & 117.32 & $p=0.488, t=-0.031$ \\
\hline Median & 117.00 & 117.20 & \\
\hline Range & $109.00-127.50$ & $106.5-127.5$ & \\
\hline \multicolumn{4}{|l|}{$\mathrm{Hb}(\mathrm{g} / \mathrm{dL})$} \\
\hline Mean & 10.19 & 12.58 & $p=0.004, t=-3.021$ \\
\hline Median & 10.1 & 12.5 & \\
\hline Range & $8.3-11.4$ & $11.5-14.3$ & \\
\hline \multicolumn{4}{|c|}{ Ferritin $(\mu \mathrm{g} / \mathrm{L})$} \\
\hline Mean & 15.30 & & \\
\hline Median & 9.40 & & \\
\hline Range & $3.40-43.00$ & & \\
\hline \multicolumn{4}{|c|}{$\mathrm{CRP}(\mathrm{mg} / \mathrm{L})$} \\
\hline Mean & 1.80 & & \\
\hline Median & 1.00 & & \\
\hline Range & $1.00-8.00$ & & \\
\hline
\end{tabular}

Seventy-five $(38.7 \%)$ of these learners were found to be anaemic and qualified for iron studies. Of the 75, 19 had IDA (9.8\%) (ferritin $<12 \mu \mathrm{g} / \mathrm{L}$ and CRP $<10 \mathrm{mg} / \mathrm{L}$ ). Fifty-six had normal ferritin levels; of these, $11(5.7 \%)$ had severe anaemia $(\mathrm{Hb}<10 \mathrm{~g} / \mathrm{dL})$ and were thus also included in the cases, leaving 45 cases $(23.2 \%)$ of mild nonIDA. There were more girls ( 11 out of $19,58 \%$ ) who were found to have IDA, and of the 11 learners with severe non-IDA anaemia, there were six boys (55\%) and five girls. The final study sample of 90 participants comprised 60 controls and 30 cases (experimental group). In matching the controls to the cases, the initial criteria for close matching could not be sustained; we were left with a control group rather than matched controls.

The mean weight of the boys $(20.97 \mathrm{~kg})$ did not differ statistically from that of the girls $(20.47 \mathrm{~kg})$, and neither did their height (116.83 v. $116.86 \mathrm{~cm})$. There were also no statistically significant differences in anthropometry of the cases and the controls (Table 1). Compared with the CDC's NCHS data, 23\% of the learners had a weight-forage below the 5th percentile, and $19.3 \%$ had a height-for-age below the 5th percentile. There was no difference between the genders, or controls v. cases with regard to either stunting or underweight. The association between IDA and scholastic performance is shown in Table 2. Five learners had reports for only the 4th term, and 15 had reports for the $3 \mathrm{rd}$ and 4 th terms, i.e. two reports, because of
Table 2. Comparison of scholastic performance scores between cases and controls

\begin{tabular}{lllll}
\hline Subject & Cases, $N=\mathbf{2 9}$ & Controls, $N=59$ & $p$-value & $\chi^{2}$ \\
\hline Mathematics & & & 0.511 & $1.34, \mathrm{df}=2$ \\
Mean & 2.88 & 2.87 & & \\
Median & 3.0 & 3.0 & & \\
Range & $1.0-4.0$ & $1.0-4.0$ & & \\
SD & 6.54 & 6.57 & &
\end{tabular}

Life skills

$0.00017 \quad 22.36, \mathrm{df}=4$

$\begin{array}{lll}\text { Mean } & 2.93 & 3.23 \\ \text { Median } & 2.8 & 3.0 \\ \text { Range } & 2.0-4.0 & 2.0-4.0 \\ \text { SD } & 5.35 & 5.54\end{array}$

Literacy

Mean $\quad 2.64 \quad 2.76$

Median $\quad 2.8 \quad 3.0$

Range $\quad 1.0-4.0 \quad 1.0-4.0$

$\begin{array}{lll}\mathrm{SD} & 7.29 & 6.39\end{array}$

$\mathrm{df}=$ degrees of freedom.

transfers between the schools. The remaining 70 learners had reports for all four terms. As indicated in Table 2, mathematics scores ranged from $1.0-4.0$ for both the cases and the controls, with a mean of 2.88 and 2.87, respectively; there was no statistically significant difference in the two groups $(p=0.511)$. There was also no significant genderrelated difference in the mathematics scores $\left(\chi^{2}=0.51, \mathrm{df}=2, p=0.511\right)$. In literacy the means were different, with 2.64 for cases and 2.78 for controls; the $p$-value approached significant levels $(p=0.071)$. No gender differences were found between the scores $\left(\chi^{2}=0.33, \mathrm{df}=2\right.$, $p=0.845$ ). Life skills was the only area with a wide difference in the scores: the cases had a mean of 2.93 and controls had a mean of 3.23. For life skills, a statistically significant difference was found between cases and controls, with the control group, as expected, having better scores $(p=0.00017)$. No gender differences were found between the scores $(p=0.592)$.

\section{Discussion}

The point prevalence for IDA in the poorly resourced Winterveldt area was found to be $9.8 \%$, which is clinically important but somewhat less than the previous studies. For instance, a study in the Western Cape Province indicated a range of $32-46 \%,{ }^{[4]}$ a study by Van Stuijvenberg et al. ${ }^{[5]}$ conducted in KZN indicated a prevalence of $27.8 \%$ among 6 - 11-year-old primary school learners, and a study conducted in the Northern Cape Province found the prevalence of ID to be $30.6 \%{ }^{[6]}$ The results of this study and the previous studies may be due to the overall poor socioeconomic status that prevails in the rural and periurban areas of SA.

However, more recent studies paint a different picture. The South African Vitamin A Consulting Group (SAVACG) survey in 1995 found a prevalence of $5.0 \%$ of IDA, ${ }^{[23]}$ the National Food Consumption Survey (NFCS) (2005) study a prevalence of $11.3 \%{ }^{[24]}$ and the South African National Health And Nutrition Examination Survey (SANHANES) a low prevalence of $1.9 \% \cdot{ }^{[25]}$ Cumulatively, the studies indicate that there is a reduction in IDA in the country as a whole. In the study area, the consumption of dark leafy vegetables such as spinach and morogo as well as samp and beans is common, and the latter are also included in the school feeding scheme. 
Anaemia (from all causes) was also found to be highly prevalent among the participants in this study (38.7\%), which could be related to the poor nutritional status of the subjects or other confounding factors such as helminth or chronic infections, particularly HIV/ AIDS and tuberculosis. In previous national surveys such as the SAVACG survey in 1995, a lower prevalence of $21.4 \%$ was found, ${ }^{[23]}$ and in the NFCS study prevalence was $28.9 \%{ }^{[24]}$ A comparison of recent studies from four provinces indicated a lower prevalence of anaemia, ranging from $7.1 \%$ in the North West Province to $20.9 \%$ in KZN. ${ }^{[26]}$ In the recent SANHANES, the anaemia prevalence was even lower at $10.7 \%{ }^{[25]}$ It therefore appears that the anaemia prevalence in primary learners has declined in most areas in SA. ${ }^{[25,26]}$ This makes the high prevalence of anaemia, nearly $40 \%$, in our study the more perplexing, as is the fact that nearly three-quarters of the anaemic cases are non-IDA anaemia. IDA is a preventable cause of cognitive impairment. The purpose of the study was to explore the effects of IDA on scholastic performance. The results of the research indicated a negative correlation between IDA and performance in such learning areas as life skills and languages. These findings are consistent with the literature. The control group scored better in life skills compared with the experimental group $(p=0.00017)$ and this is in agreement with most of the studies where learners with IDA performed poorly in general knowledge..$^{[12,16]}$ The subject of life skills, also known as life orientation, intends to equip learners for successful and meaningful living in our rapidly changing society. Its aim is to develop skill, knowledge, values and attitudes that empower learners to make informed and morally responsible decisions and act responsibly with regard to health promotion, and their own social, personal and physical development and movement. ${ }^{[27]}$ The results of this study, which show a statistically significant difference between the scores of learners with IDA compared with non-anaemic learners, with controls achieving higher scores, are in line with the findings of previous studies. ${ }^{[12]}$ As indicated by a study by the CDC in the USA, ${ }^{[9]}$ this could suggest possible cognitive impairment among the learners with IDA. Such an impairment could be making it difficult for them to make informed and accountable decisions and take appropriate actions for successful living. The test for literacy and IDA approached significance $(p=0.071)$. The small sample size could have influenced this result. However, the association between IDA and mathematics was not statistically significant, which was contrary to previous studies that found a positive correlation between IDA and poor mathematics scores ${ }^{[13,14]}$ Such findings may be attributed to low standards of mathematical knowledge expected in SA schools. Over the past few years, research has indicated that SA schoolchildren perform poorly in mathematics compared with the rest of the world. ${ }^{[28-30]}$ In the SACMEQ III report ${ }^{[31]}$ (one of the Department of Basic Education's publications) it was found that only $30 \%$ of grade 6 learners possess adequate numeracy skills. If more than two-thirds of learners are so poor at mathematics, or rather arithmetic, then it is logical to conclude that the quality of the teaching and the standards required are not adequate; and that these deficiencies probably start in grade 1. Therefore, the fact that the average of the two groups in our study is the same, and that the learners are allocated rather high scores in the early grades ( 2.9 out of a possible maximum of 4 ; i.e. an average of $72.5 \%$ ) is not surprising, and reflects the low standards. We therefore conclude that grade 1 school mathematics assessments cannot discriminate between learners who have good skills in mathematics and those who do not. Furthermore, these assessments would not be able to pinpoint learners who suffer cognitive impairment due to nutritional causes. SA has an IDA policy on iron supplementation in children and food fortification legislation (2003), ${ }^{[32]}$ but there is no comprehensive monitoring on the coverage of both policies. It has been shown that fortifying brown bread has not affected the iron status in SA children. ${ }^{[33]}$ Researchers have speculated that the food fortification programme is ineffective as they calculated that at the current dosage the bioavailable elemental iron is too low. ${ }^{[26]}$ We feel that since iron screening is not done routinely in infants, the exact magnitude of the problem is unknown. Therefore, infants are not routinely given supplements and early treatment is not given. Since dietary history and knowledge of fortified foods was not investigated, we cannot draw conclusions as to whether these fortified foods had been consumed by the study population. The poor socioeconomic status of our study population, however, would make it quite possible that fortified foods are unlikely to be consumed by them. The following recommendations can assist in alleviating the problem of high prevalence of IDA and anaemia:

- Infants should be the target group for screening and treatment because they are at the age of accelerated brain growth, and some studies show that once the damage is done, the effects cannot be reversed.

- Iron supplements should be provided during the first 3 years of life, targeting the poor/vulnerable communities. Although this is feasible up to the age of 18 months, which coincides with the 18 months vaccines, it can be achieved by increased awareness of the micronutrient deficiencies.

- Brief educational sessions to enhance awareness should be offered at the clinics when parents bring their infants for vaccinations.

\section{Study limitations}

Firstly, in view of the small sample size, the results may not be generalisable to all children. Furthermore, the school report used as an instrument for this study may not have been the best measure of school performance as its validity and reliability were not tested. Factors which may affect school performance, such as parental education, marital status and socioeconomic status have not been accounted for in the study, although we know that in general, Winterveldt is a low socioeconomic area. Furthermore, it is not clear what the quality of the schools' education is, although one can again speculate that as they are all rural schools they are unlikely to be excellent. Nevertheless, the results of this study were largely consistent with the literature and were representative of primary school-going learners in the Winterveldt area.

\section{Conclusion}

This study provides evidence that IDA may have negative effects on school performance. Such negative effects warrant early preventive measures so as to avoid the possibilities of school failure, drop-out and eventually poor productivity in the adult population.

Acknowledgements. We would like to thank the school and the learners who took part in the study and their parents.

Source of funding. Department of Paediatrics and Child Health, Medical University of Southern Africa (MEDUNSA), Faculty of Medicine (University of Limpopo), Pretoria.

\section{References}

1. Wu AC, Lesperance L, Bernstein H. Screening for iron deficiency. Pediatr Rev 2002;23(5):171-178. DOI:10.1542/pir.23-5-171

2. Hall A, Bobrow E, Brooker S, et al. Anaemia in school children in eight countries in Africa and Asia. Public Health Nutr 2001;4(3):749-756. DOI:10.1079/ PHN2000111

3. Faber M, Wenhold F. Nutrition in contemporary South Africa. Water SA 2007;33(3):393-400. http://www.wrc.org.za (accessed 15 June 2013).

4. Jacobson D. Prevention and treatment of iron deficiency anaemia in children Cont Med Educ 2008;26(5):242-244.

5. Van Stuijvenberg ME, Kvalsvig JD, Faber M, et al. Effect of iron-, iodine- and $\beta$-carotene-fortified biscuits on the micro-nutrient status of primary schoo children: A randomised controlled trial. Am J Clin Nutr 1999;69(3):497-503.

6. Troesch B, van Stuijvenberg ME, Smuts CM, et al. A micronutrient powder with low doses of highly absorbable iron and zinc reduces iron and zinc deficiency and improves weight-for-age Z-scores in South African children. J Nutr 2011;141(2):237-242. DOI:10.3945/jn.110.129247 
7. Miller DR, Baehmer RL. Blood diseases of infancy and childhood. 6th ed. St Louis: The OCV Mosby Company, 1995:170-175.

8. Nathan DG, Orkin SH. Nathan and Oski's Haematology of Infancy and Childhood. 5th ed. Pennsylvania, WB Saunders, 1998:425-441.

9. Centers for Disease Control and Prevention. Recommendations to prevent and control of iron deficiency in the USA. MMWR Morbidity, Mortality Weekly Report. 1998. http://www.cdc.gov/mmwr/pdf/rr/rr4703.pdf (accessed 18 June 2013)

10. Angeles IT, Schultink WJ, Matulessi P, et al. Decreased rate of stunting among anaemic Indonesian preschool children through iron supplementation. Am J Clin Nutr 1993;58(3):339-342.

11. Berry L, Hall K, Hendricks M. Nutrition - Stunting in Children. Cape Town: Children's Institute, University of Cape Town, 2010. http://www.childrencount. ci.org.za (accessed 29 October 2014).

12. Pollitt E. Iron deficiency and educational deficiency. Nutr Rev 1997;55(4):133141. DOI:10.1111/j.1753-4887.1997.tb06464.x

13. Stoltzfus RJ, Mullany L, Black RE. Iron deficiency anaemia. In: Ezzati M, Lopez $\mathrm{AD}$, Rodgers A, Murray CJL, eds. Comparative quantification of health risks: Global and regional burden of disease attributable to selected major risk factors. Geneva: World Health Organization, 2004:163-209.

14. Sungthong R, Mo-suwan L, Chongsuvivatwong V. The effects of haemoglobin and serum ferritin on cognitive function in school children. Asia Pac J Clin Nutr 2002;11(2):177-182. DOI:10.1046/j.1440-6047.2002.00272.x

15. Lozoff B, Jimenez E, Smith JB. Double burden of iron deficiency in infancy and low socioeconomic status: A longitudinal analysis of cognitive tests scores to age 19 years. Arch Pediatr Adolesc Med 2006;160(11):1108-1113. DOI:10.1001/ archpedi.160.11.1108

16. Aboussaleh Y, Ahami A, El Hioui M, Bonthoux F. Cognitive Performance of Anaemic School Children. North-western Morocco. Micronutrient Forum Meeting. http://www.micronutrientforum.org/meeting2009/PDFs/Poster\%20 Presentations/4Friday/MCHDO/F66-Aboussaleh.pdf (accessed 15 September 2009)

17. Statistics South Africa. Census 2011. Pretoria: Statistics South Africa, 2011. http://beta2.statssa.gov.za/?page id =3839 (accessed 27 October 2014).

18. Schools4SA. Schools in Winterveldt at Schools4SA. South Africa. 2014. http:// www.schools4sa..co.za/province/gauteng/winterveldt/ (accessed 27 October 2014)

19. Ali A, Fathy GA, Fathy HA, El-Ghaffar NA. Epidemiology of iron deficiency anaemia: Effect on physical growth in primary school children, the importance of hookworms. Int J Acad Res 2011;3(1):495-500. DOI:10.7813/20754124.2011/3-1/B.73

20. Ferreira MU, da Silva-Nunes M, Bertolino CN, Malafronte RS, Muniz PT, Cardoso MA Anaemia and iron deficiency in school children, adolescents, and adults: A community-based study in rural Amazonia. Am J Pub Health 2007;97(2):237-239. DOI:10.2105/AJPH.2005.078121

21. World Health Organization. Iron Deficiency Anaemia: Assessment, Prevention and Control. A Guide For Programme Managers 2001. http://www.int/ nutrition/publications/en/ida_assessment_prevention_control.pdf (accessed 29 October 2014).

22. HemoCue Products. 2004. http://www.hemocue.com/index.php?page $=2004$ (accessed 23 March 2009)

23. Labadarios D, van Middelkoop A, eds. Children aged 6 - 71 months in South Africa 1994: Their anthropometric, vitamin A, iron and immunisation coverage and status. The South African Vitamin A Consulting Group (SAVACG): Johannesburg 1995. http://indicators.hst.org.za/healthstats/211/data\#sthash. zRy85Nko.dpuf (accessed 26 October 2014)

24. Labadarios D, ed. The National Food Consumption Survey-Fortification Baseline (NFCS-FB): South Africa, 2005. Stellenbosch: National Department of Health; 2007.

25. Shisana O, Labadarios D, Rehle T, et al. South African National Health and Nutrition Examination Survey (SANHANES-I). Cape Town: Human Sciences Research Council Press, 2013.

26. Taljaard C, Covic NM, Van Graan A, Kruger HS, Jerling JC. Studies since 2005 on South African primary schoolchildren suggest lower anaemia prevalence in some regions. S Afr J Clin Nutr 2013;26(4):168-175.

27. National Department of Education, South Africa. HIV and AIDS Lifeskills and Sexuality Education Primary School Programme Resource Guide. Pretoria: SA Government Publishers, 2006. http://www.thutong.doe.gov.za/Default.aspx? (accessed 3 January 2015).

28. Howie S. Mathematics and Science Performance in Grade 8 South Africa 1998/1999. Pretoria: Human Sciences Research Council, 2001.

29. Siyepu S. The zone of proximal development in the learning of mathematics. S Afr J Educ 2013;33(2):1-13.

30. Bansilal S, James A, Naidoo M. Whose voice matters? Learners. S Afr J Educ 2010;30(1):153-165.

31. Moloi MQ, Chetty M. The SACMEQ III Project in South Africa: A Study of The Conditions of Schooling and the Quality of Education. Pretoria: Department of Basic Education, 2010.

32. National Department of Health, South Africa. Foodstuffs, Cosmetics and Disinfectants Act No. 54 of 1972. Pretoria: NDoH, 2003. http://www.doh.gov. $\mathrm{za} /$ docs/regulations/2003/Regulations_Fortification.pdf (accessed 3 January 2015).

33. Van Stuijvenberg ME, Smuts CM, Lombard CJ, Dhansay MA. Fortifying brown bread with sodium iron EDTA, ferrous fumarate, or electrolytic iron does not affect iron status in South African school children. J Nutr 2008;138(4):782-786. 